Kohl: a Journal for Body and Gender Research

Vol. 2, No. 1 (Summer 2016)

\title{
Neither Victim nor Savage: \\ Pleasure in Resistance, Resisting (with) Violence
}

Ghiwa Sayegh 
From Baghdad, to Istanbul, to Dhaka, violence and grief are devastating. Every location, every city we have lived in, or walked through, or dreamed of, or even never known or heard of seems to be crumbling under the weight of centuries of inequalities and occupations and homegrown oppressions. As new geographies start to emerge, our atlas of the world is shaken by horrid images, to which we become a bit more immune every day. Despite my discomfort with universalizing frameworks, I cannot but recognize that violence, bombings, police brutality, crackdowns, shootings, incarceration, torture, and wars are pervasive, no matter where we go. And we live with the overpowering realization that no place is safe for non-white, working class bodies.

"Beyond Victims and Savages: The Complexities of Violence, Resistance, and Pleasure" could not be more timely. Working on the issue for the past six months and delving into accounts, narratives, and politics of resistance that refuse the equation of victim/savage was by itself a collective act of resistance. This collection speaks against the oppressive violence we are experiencing in groups of marginalized and tokenized communities, whether at the hands of sensationalized, violent oppression or those of liberal and right-wing representations and monolithic discourses. Ultimately, writing back, thinking back, and organizing back intersectionally as brown leftist feminists provide a powerful alternative to the mainstreaming of gender and the normalization of suffering.

Going beyond the dichotomy of victims and savages entails a nuanced understanding of violence. Such an understanding perceives mainstream violence as indivisible from other paradigms of large-scale oppression - hegemony, socioeconomic injustice, institutionalization, neoliberalism, occupation... It also accounts for the normalized violence we live on a daily basis, in silent acts of coercion, harassment, bullying, and selfdamage, and the ways in which they are informed by macro instances of violence, and vice versa. But most importantly, historicizing violence requires the recognition and celebration of pleasure and resistance, even in violent contexts. It challenges our stance on certain acts perceived as violence, especially in contexts of self-care, self-protection, consensual pleasure, and resistance movements.

The issue opens with an artistic intervention by Tanja Van Deer and Saba Sadr with the support of Salwa Mansour, who vandalized a jewelry billboard to expose and subvert its capitalist and sexist message. The arto-political action follows the path of "culture jamming," as defined by the artists.

In a sharp opinion piece, Nadje Al-Ali challenges the ways in which we talk about violence, reaffirming her rejection of dichotomies. Her discomfort with western-based representations of violence experienced elsewhere, particularly the Middle East and Iraq, is validated by apologetic discourses that stem from issues of positionality, whether from within or in diaspora. Disconcerted by the trend that tends to focus on representations of violence rather than addressing the violence lived by the very same subjects of representation, she calls for more on-the-ground research to mitigate the hegemony of discourse and representation.

Further criticizing the politics of representation, this issue's "Openings" discussion moderated and edited by Jana Nakhal grapples with the various ways non-normative bodies are silenced and accounts for their spaces 
of agency, whether in traditional family roles, in language, or in public sex talks. The conversation also questions whether pleasure is a trope of resistance or internal violence, and closes by revisiting agency and the masculine gaze in sex work and porn.

In "Queering BDSM, Losing the Labels: A Circular Methodology," Lady Gya dissociates pain from violence. Instead, she links consensual sexual practices, notably BDSM, to resistance and pleasure. Weaving stories of sex with narratives of violence, she challenges the conventions that exist not only in heteronormative milieus, but also in certain queer communities and feminist ideologies. The testimony is a daring and provocative read about a practice that has long been stigmatized and shunned, even by radical circles.

The second testimony, "Compulsory Military Service and Gender in Druze Communities under Occupation," is Maisan Hamdan's, a founding member of the group "Refuse, Your People Will Protect You." Hamdan exposes the sociohistorical layers of compulsory military service that Druze young men undergo in the occupying state of Israel, and explores the gendered aspects of conscription. Most importantly, she denounces the coercion of young Druze by the state authorities and social pressure into accepting a militarized future at the service of their occupier.

Not too far from Hamdan's sociohistorical reading of macro- and micro-factors of community formations and social pressure, Kenza Yousfi revisits "Community Organizing and National Liberation in the Sahawari Feminist Politics." In the first research article of this issue, Yousfi engages in a rare ethnography conducted in the Saharawi camps of Tindouf, Algeria. Her careful analysis challenges the notions of violence and statebuilding, weaving in a feminist lens of resistance. By not dismissing militarized resistance, Yousfi contends, looking at alternative ways of community organizing becomes possible.

With "'The Daughters of Egypt are a Red Line:' The Impact of Sexual Harassment on Egypt's Legal Culture," Mariam Kirollos delivers the second research article of this issue. She explores the dimensions of the new Egyptian law that criminalizes sexual harassment in local and international cases and reports, and traces the legal culture back to the historical public sexual harassment cases that were headline news in various newspapers and portals. Kirollos' timely piece uncovers the expectations of activists and organizations to hold the state accountable.

In contrast, Susana Galán distances her research from "the logic of state protection," hinting at her skepticism with regard to criminalization laws. Instead, she delves into the politics of self-defense, and reads it through the various ways it has been used by feminists, rioters, and communities in Cairo to repel sexual harassment and collective sexual assaults. Ranging from mainstream approaches to alternative modes of self-care and self-protection, Galán's research lucidly accounts for both the work of organizations such as OpAntiSH and WenDo and the shift in public discourse after the Egyptian Revolution of 2011, countering the legal discourse of the state.

Siwar Masannat gives us a powerful literary reading of Hoda Barakat's Disciples of Passion, the final research piece of this issue. Masannat's nuanced analysis of queer affects in the novel, imbricated with notions of 
collective memory, is a pleasure to read. She grapples with the aftermath of war violence on the human's psyche, as well as the violence embodied by institutions such as mental health facilities. These types of violence intersect with the image of a beloved woman, who is within and without the novel's narrator. The article delicately enfolds and highlights the discontinuity of memory and perception, breaking the dichotomies of real and imagined and reconfiguring desire in the process.

Still in the spirit of literary pieces, Jessika Khazrik's poem, "Mount Mound Refuse," is a subversive text that poses a challenge to the standardized limits of language and syntax. Khazrik's surrealist style freely runs on paper. She unearths the discontinuities of thought, and by doing so, transgresses the norms of coherent speech devoid of repetitions and obsessive recurrences. The poetess and performer insisted on translating the poem herself, delivering a powerful text that blends the Arabic language with random English outbursts.

The issue closes with two reviews of books that have made us dream, think, and write. The first one, by Arianne Shahvisi, is a review of Sahar Mandour's 32. Newly translated to English, 32 is a jewel of Arabic literature by the young novelist and Kohl advisor. Shahvisi, who has lived in Beirut, nostalgically reads the novel with raw positionality. She notices the juggling of violence with tender, sometimes comical everyday details, and while Beirut is the beginning and end of the novel, Shahvisi notes that it does not conform to stereotypes about life in Beirut, although it grazes them with fresh emotions and intensity.

Roua Seghaier, Kohl's associate editor, reviews Angela Davis' Freedom is a Constant Struggle: Ferguson, Palestine, and the Foundations of a Movement. Seghaier highlights the intersections of history, memory, resistance, and movement building in times of violence. The collection of interviews, essays, and speeches transnationally identify violence and discrimination of marginalized groups across time and geopolitical borders, including prisons, and Seghaier is quick to denote the many overlaps of the prison industrial complex with the Palestinian struggle and Ferguson, raised by the book.

Collaborating with such amazingly fierce authors and feminists was humbling. They remind us, through their research and art, not to further silence the subjects of violence, but to acknowledge and support their political resistance without appropriation or dismissal. Their careful considerations of the many overlaps of violence, resistance, and pleasure from within broader systems of injustice expand on the politicized act of feminist writing and knowledge production as a tribute to and celebration of the lives we've lost and those that won't be commemorated. 